\title{
Narrativas de professoras dos anos iniciais sobre a matemática na sua trajetória formativa e profissional
}

\author{
Letícia Freitas Fernandes ${ }^{1}$ \\ UFJF, Faculdade de Educação, Juiz de Fora, Minas Gerais, Brasil.
}

\begin{abstract}
Sandra Alves de Oliveira ${ }^{2}$
UFJF, Faculdade de Educação, Programa de Pós-Graduação em Educação, Juiz de Fora, Minas Gerais. UNEB, Campus XII, Guanambi, Bahia. CMAJO, rede municipal de ensino de Candiba, Bahia, Brasil.
\end{abstract}

\section{Resumo}

Esta pesquisa focaliza os processos formativos de quatro professoras de matemática dos anos iniciais da rede de ensino pública e privada de Juiz de Fora, participantes do curso de Especialização em Ensino de Ciências e Matemática nos Anos Iniciais da Faculdade de Educação (FACED) da Universidade Federal de Juiz de Fora (UFJF), Minas Gerais, de 2019 a 2020. Analisam-se os sentidos por elas atribuídos à matemática na sua trajetória formativa e profissional; e identificam-se contribuições e desafios da formação inicial e continuada para práticas de ensino em matemática na educação básica. Os referenciais teóricos ancoram-se nos estudos sobre formação matemática e prática de ensino de professores dos anos iniciais. As professoras compartilharam, em entrevistas narrativas, as aprendizagens da docência na formação continuada e enfatizaram a articulação das vivências nos encontros desse curso com suas práticas ao ensinar matemática. Salientaram as lacunas evidenciadas em sua trajetória formativa: o desafio de entender os conteúdos matemáticos; a carga horária reduzida de Matemática no curso de Pedagogia, voltada aos conteúdos específicos da matriz curricular da escola básica; a ausência de melhor articulação entre os conhecimentos teóricos e práticos na formação inicial. O estudo revelou a importância da formação inicial e continuada para o aprofundamento teórico e prático dos fundamentos da matemática na trajetória formativa e profissional. O grupo participante da pesquisa enfatizou a relevância do entusiasmo e da alegria, que tornam as aulas de matemática mais prazerosas, dinâmicas e desafiadoras.

Palavras-chave: Formação matemática; Ensino-aprendizagem; Desenvolvimento profissional.

${ }^{1}$ Graduação em Pedagogia e Especialização em Ensino de Ciências e Matemática nos Anos Iniciais pela Faculdade de Educação da Universidade Federal de Juiz de Fora. Rua José Lourenço Kelmer, s/n, Campus Universitário, Bairro São Pedro, Juiz de Fora-MG. CEP: 36036-900. E-mail: leleticiaff@ gmail.com.

${ }^{2}$ Doutoranda em Educação pela Universidade Federal de Juiz de Fora. Rua José Lourenço Kelmer, s/n, Campus Universitário, Bairro São Pedro, Juiz de Fora-MG. CEP: 36036-900. Professora do Campus XII/UNEB (Guanambi-BA). Professora do Colégio Municipal Aurelino José de Oliveira (Candiba-BA). Integra os grupos de pesquisas: NEPE/UNEB; GEM/UFSCar; GREPEM/UFJF. E-mail: saoliveira@uneb.br. 
Narratives of early childhood teachers about mathematics in their formative and professional

\title{
trajectory
}

\begin{abstract}
This research focuses on the training processes of four early childhood mathematics teachers from the public and private education in Juiz de Fora, from the Specialization course in Science and Early Childhood Mathematics Teaching of the College of Education (FACED) - the Juiz de Fora Federal University (UFJF), Minas Gerais, from 2019 to 2020. We analyzed the meanings attribute to mathematics in their formative and professional trajectory and identified contributions and challenges from initial and continuing education to teaching practices of mathematics in basic education. Theoretical frameworks are anchored in studies on mathematical training and teaching practice of teachers in childhood education. The teachers shared, in narrative interviews, the learning of teaching on continuing education and emphasized the articulation of the experiences in the meetings of this course with their practices when teaching mathematics. They highlighted the gaps evidenced in their formative trajectory: the challenge of understanding mathematical content; the reduced workload of Mathematics in the Pedagogy course, focused on the specific contents of the curricular matrix of the basic school; the absence of a better articulation between theoretical and practical knowledge in initial training. The study revealed the importance of initial and continuing education for the theoretical and practical deepening of the foundations of mathematics in the formative and professional trajectory. The respondents in the research emphasized the relevance of enthusiasm and happiness, which make math classes more enjoyable, dynamic, and challenging.
\end{abstract}

Keywords: Mathematical formation; Teaching-learning; Professional development.

\section{Resumen}

\section{Narrativas de profesoras en los primeros años sobre las matemáticas en su trayectoria}

\section{formativa y profesional}

Esta investigación se centra en los procesos de formación de cuatro profesores de matemáticas de los primeros años de la red educativa pública y privada de Juiz de Fora, quienes participaron en el curso de Especialización en Enseñanza de las Ciencias y las Matemáticas en los Primeros Años de la Facultad de Educación (FACED) de la Universidad Federal de Juiz de Fora (UFJF), Minas Gerais, de 2019 a 2020. Se analizaron los sentidos que atribuyeron a las matemáticas en su trayectoria formativa y profesional; se identificaron las contribuciones y desafíos desde la educación inicial y continua a las prácticas docentes en matemáticas en la educación básica. Los marcos teóricos están anclados a estudios sobre la formación matemática y la práctica docente de los profesores en los primeros años. Las profesoras compartieron, en entrevistas narrativas, el aprendizaje de la docencia en la educación continua y enfatizaron la articulación de las experiencias en los encuentros de este curso con sus prácticas en la enseñanza de las matemáticas. Destacaron las brechas evidenciadas en su trayectoria formativa: el desafío de comprender los contenidos matemáticos; la reducida carga de trabajo de Matemáticas en el curso de Pedagogía, enfocado en los contenidos específicos de la matriz curricular de la escuela básica; la ausencia de una mejor articulación entre conocimientos teóricos y prácticos en la formación inicial. El estudio reveló la importancia de la educación inicial y continua para la profundización teórica y práctica de los fundamentos de las matemáticas en la trayectoria formativa y profesional. El grupo que participó en la investigación enfatizó la relevancia del 
entusiasmo y la alegría, que hacen que las clases de matemáticas sean más divertidas, dinámicas y desafiantes.

Palabras claves: Formación matemática; Enseñanza-aprendizaje; Desarrollo profesional.

\section{Introdução}

No percurso formativo da primeira autora deste artigo, estudante do curso de Especialização em Ensino de Ciências e Matemática nos Anos Iniciais da Faculdade de Educação (FACED) da Universidade Federal de Juiz de Fora (UFJF), estado de Minas Gerais, no período de 2019 a 2020, a matemática era uma incógnita, pois a aluna não entendia muito bem os conteúdos apresentados e discutidos pelos professores. Foi assim em muitos momentos da sua trajetória estudantil na educação básica. Somente na graduação, nas disciplinas voltadas às metodologias de ensino-aprendizagem da matemática, começou a vê-la de maneira diferente. Isso porque, como afirmam Martins e Curi (2020, p. 4), "é na sala de aula que se manifestam não somente o conhecimento matemático do professor, mas também são exteriorizadas as suas crenças e concepções sobre a Matemática e o seu ensino”, reveladas nas práticas pedagógicas.

No término da graduação, teve a oportunidade de atuar numa turma de $3^{\circ}$ ano do ensino fundamental. Ao chegar à sala de aula, deparou-se com a dificuldade de ensinar, sem perceber que repetia as mesmas práticas de alguns de seus professores do seu percurso formativo e transformava a matemática em uma disciplina repetitiva, mecanizada e monótona. Com efeito, o processo de ensinoaprendizagem da matemática não deve ocorrer "por repetições e mecanizações", mas sim por meio "de uma prática social que requer envolvimento do aluno em atividades significativas" (NACARATO; MENGALI; PASSOS, 2009, p. 34) vivenciadas em sala de aula.

A prática pedagógica da professora não possibilitou o envolvimento de seus estudantes nas aulas de matemática, e ela, assim, percebia o desinteresse deles no processo de ensino-aprendizagem. Diante da situação, sentiu a necessidade da formação continuada para romper com o modelo de aula tradicional enraizado na sua atuação como professora: papel central da exposição dos conteúdos, usando os livros-texto e a resolução de exercícios, sem possibilitar a participação dos estudantes nas discussões em sala de aula. Com efeito, “[...] as aulas tradicionais de matemática influenciam a comunicação entre alunos e professores de um jeito próprio" (ALRØ; SKOVSMOSE, 2006, p. 16) de cada professor(a) ensinar e possibilitam a participação dos estudantes durante a explicação dos conteúdos e a resolução das questões propostas.

A proposta desta pesquisa partiu da experiência da professora com a matemática e também de observações e questionamentos nas aulas da Especialização, principalmente, em disciplinas 
relacionadas ao ensino de matemática. A maioria das estudantes da turma relatou dificuldades em ensinar os conteúdos de matemática, por não terem conhecimentos de como ensiná-los. A partir desses relatos, surgiram indagações das estudantes, tais como: "Como posso manter o interesse e o foco de meus estudantes em uma aula de matemática?", "Como ensinar uma disciplina de que eu não tenho o domínio?". Com isso, veio a necessidade de um estudo mais aprofundado para contribuir com o processo formativo inicial e continuado das professoras que ensinam matemática, participantes da pesquisa.

De acordo com Costa, J., Pinheiro e Costa, E. (2016, p. 506), “[...] se a atuação do professor na escolarização inicial do indivíduo for falha, poderá interferir de forma negativa na continuidade do processo educativo". Os autores salientam a importância das metodologias vivenciadas na prática docente e ressaltam como a primeira experiência pode deixar marcas profundas nos estudantes.

Segundo Gatti (2013, p. 54), “a preocupação com a educação escolar, com a escola, nos reporta a pensar em pessoas, em relações pedagógicas intencionais, portanto, em profissionais bem formados para isso". O principal questionamento dos pesquisadores da área da educação e da educação matemática é: como formar um profissional para atuar em todas as áreas do conhecimento?

Conforme Carneiro e Passos (2014a, p. 977), “o pedagogo é formado para atuar na Educação Infantil, nos anos iniciais do Ensino fundamental e também na Educação de Jovens e Adultos, por isso, contempla uma gama de conhecimentos relativos às diversas disciplinas presentes no currículo escolar [...]". É ampla a área de atuação do pedagogo, o que nos leva a refletir sobre os desafios de um curso de graduação em Pedagogia para formar profissionais para atuar em áreas tão distintas do conhecimento, tais como: Língua Portuguesa, Matemática, Geografia, História, Ciências, dentre outras.

Nacarato, Mengali e Passos (2009, p. 22) apontam que "as professoras polivalentes têm tido poucas oportunidades para uma formação em matemática que possa fazer frente às atuais exigências da sociedade [...]”, principalmente, no que diz respeito à formação inicial. Portanto, é importante que estudos e pesquisas possam contribuir com esse processo, frente às novas demandas culturais e sociais.

Esta pesquisa partiu de uma demanda real, de questionamentos de professoras que atuam na educação básica e buscaram o curso de Especialização como um espaço para expor suas experiências, dificuldades, aflições, inseguranças e aprendizagens. E quais seriam os desafios, as contribuições e os sentidos atribuídos à matemática por professoras dos anos iniciais da rede de ensino pública e privada de Juiz de Fora, na sua trajetória formativa e profissional?

Neste artigo, apresentamos e discutimos os resultados de uma pesquisa de Trabalho de Conclusão de Curso (TCC), que utiliza a entrevista narrativa como um instrumento metodológico que 
"reforça a capacidade humana de narrar histórias, rememorar o vivido e socializar experiências formadoras através da linguagem" (SOUZA; CRUZ, 2017, p. 183). Este estudo buscou analisar os sentidos atribuídos à matemática por professoras dos anos iniciais das redes de ensino pública e privada de Juiz de Fora, na sua trajetória formativa e profissional; e identificar as contribuições e os desafios da formação inicial e continuada para as práticas de ensino em matemática na educação básica.

Este texto, além da introdução e das considerações finais, está organizado em três seções. $\mathrm{Na}$ primeira, explicitaremos os percursos metodológicos da pesquisa. Na segunda, refletiremos sobre os processos formativos de professoras que ensinam matemática, suas concepções e os desafios no processo de ensino-aprendizagem e os sentidos do "desempacotar" as práticas de ensino em matemática. Na terceira, compartilharemos as narrativas da formação inicial e continuada, contadas por professoras que atuam na educação básica.

\section{Percursos metodológicos trilhados na investigação}

Nesta pesquisa, a formação matemática de professoras que ensinam nos anos iniciais do ensino fundamental inquietou-as e levou-as a investigar as histórias de experiências que constituíram a trajetória formativa e profissional "no meio do viver e do contar, do reviver e recontar [...] que compuseram as vidas das pessoas em ambas as perspectivas: individual e social" (CLANDININ; CONNELLY, 2015, p. 51), no âmbito da formação e da prática docente.

De acordo com Bolívar, Domingo e Fernández (2001, p. 121, tradução nossa), “a investigação narrativa pode ser compreendida como uma subárea dentro do amplo guarda-chuva da pesquisa qualitativa, mais especificamente como investigação experiencial" de "histórias vividas e contadas" (CLANDININ; CONNELLY, 2015, p. 51) dos processos formativos que contribuíram para o desenvolvimento profissional.

Devido à pandemia Covid-19, iniciada no mês de março de 2020, não foi possível realizar encontros presenciais, conforme planejamos, para a produção de dados desta pesquisa por meio da entrevista narrativa. As medidas sanitárias e de distanciamento social definidas pela Organização Mundial da Saúde (OMS) para contribuir com a redução da propagação do novo coronavírus levaramnos a modificar os procedimentos metodológicos da investigação e usar os recursos tecnológicos para subsidiar a pesquisa.

A orientadora, autora deste artigo, propôs enviarmos às 30 estudantes-professoras participantes do curso de Especialização, por e-mail, o Termo de Consentimento Livre e Esclarecido (TCLE). Dessa forma, pelo correio eletrônico nos apresentamos às possíveis participantes da pesquisa. Também explicitamos a finalidade de nosso estudo e as convidamos para participar. 
Somente 4 estudantes-professoras do curso de Especialização assinaram o TCLE para participar da entrevista narrativa.

Por conta da pandemia Covid-19, realizamos a entrevista narrativa em chamada de vídeo, usando o aplicativo WhatsApp. Corroboramos a afirmação de Clandinin e Connelly (2015, p. 153): "A forma como um entrevistador age, questiona e responde em uma entrevista formula uma relação e por isso os participantes respondem e dão relatos de suas experiências". Esse momento na pesquisa oportunizou às estudantes-professoras narrarem experiências com a matemática no seu percurso formativo.

O contato com as partícipes e o agendamento da entrevista foram realizados por mensagens nesse aplicativo, respeitando o isolamento social. Os nomes das participantes da pesquisa (Carla, Dandara, Mel e Silvia), estudantes-professoras, são fictícios, para preservar sua identidade. Elas participaram do processo de escolha do pseudônimo. Segundo Bolívar, Domingo e Fernández (2001, p. 163, tradução nossa), “o anonimato ou não (conforme declarado pelo entrevistado) e o direito à voz também devem fazer parte do referido acordo" na entrevista narrativa.

Para realizá-la, construímos um roteiro com perguntas abertas sobre práticas de ensino em matemática, vivenciadas na formação inicial e continuada, que contribuíram para a prática docente. Após a entrevista, os dados foram transcritos e enviados para o $e$-mail das estudantes-professoras, para que pudessem ler e complementar algo que gostariam de ter dito e não falaram, ou para retirar alguma parte do texto. Somente uma participante da pesquisa fez alteração na repetição de palavras no mesmo parágrafo da narrativa. Posteriormente, procedemos à análise dos dados, considerando o problema e os objetivos da pesquisa, compartilhados neste trabalho.

Nesse processo, a revisão bibliográfica foi fundamental para “[...] aprofundar e conhecer o que já se tem pesquisado ou estudado sobre o tema [...]” (FIORENTINI; LORENZATO, 2012, p. 84), e orientou as alterações e os aprimoramentos necessários à realização da pesquisa.

\section{Reflexões sobre os processos formativos de professores que ensinam matemática}

Diante do cenário atual da educação brasileira, no que tange à educação matemática, deparamo-nos com o desafio de discutir o ensino de matemática. "É relevante refletir sobre a formação de professores que irão atuar nos anos iniciais do ensino fundamental" (VIEIRA JUNIOR; OLIVEIRA, 2019, p. 26). Para tanto, há a necessidade de refletir sobre a formação inicial e a formação continuada desses profissionais, pedagogos, que atuam na educação básica como professores polivalentes, trazendo contribuições para o debate.

Gatti (2013, p. 64) reflete sobre a fragilidade formativa dos cursos de licenciatura, que a levou discutir sobre a formação inicial que estes oferecem aos licenciandos, e destaca que "a estrutura da 
educação básica mudou, os segmentos sociais que nela se inserem mudaram, a idade de inserção das crianças e adolescentes mudou. Essas mudanças exigem da formação de professores mudanças radicais". É necessário que as mudanças oportunizem aos graduandos participarem “mais profundamente de questões educacionais, dos aspectos de desenvolvimento cognitivo e social dos alunos que adentram a escola básica e suas motivações, questões relativas à escola e às redes de ensino, ao seu currículo, entre outros aspectos" (GATTI, 2013, p. 64) que precisam ser discutidos no percurso formativo.

Segundo Nacarato, Mengali e Passos (2009, p. 20), "as futuras professoras polivalentes têm tido poucas oportunidades para uma formação matemática que possa fazer frente às atuais exigências da sociedade e, quando ela ocorre na formação inicial, vem se pautando nos aspectos metodológicos". Mas não deveríamos julgar ou culpar a formação inicial, pois, conforme Bruno e Silva (2016, p. 38):

[...] os cursos de licenciatura e, especificamente, o curso de Pedagogia devem constituir no seu projeto pedagógico uma matriz curricular de forma equilibrada, articulada e dialogada, que contemple os saberes teóricos e práticos demandados para uma atuação profissional coerente com o contexto atual.

Carneiro e Flôr (2016) ressaltam a importância da formação permanente do professor e a participação em diferentes espaços formativos, pois estes auxiliam a produção de sentidos e significados que são incorporados à sua prática, por meio de uma inter-relação entre os conhecimentos adquiridos nos momentos de formação. Segundo Vieira Junior e Oliveira (2020, p. 713), o processo de formação deve possibilitar:

momentos de diálogos em que sejam trabalhadas questões referentes às concepções matemáticas que as futuras professoras têm deste componente. Além disso, o processo formativo deve viabilizar práticas inovadoras em sala de aula, capazes de superar um ensino marcado pela enfadonha repetição em busca da memorização sem reflexão; da matemática como conteúdo isolado de outras áreas do conhecimento; de um saber desconexo com a realidade que cerca o estudante.

Com efeito, "produzir o novo nos processos formativos é enfrentar o doloroso processo de reflexão, que envolve questionamentos: Como está minha prática pedagógica? Tenho alcançado meus objetivos? Como está a relação professor/estudante? [...]” (BRUNO; SILVA, 2016, p. 48). Dessa maneira, no que tange à formação inicial e continuada para o ensino de matemática, há desafios que precisam ser superados, como as crenças, os medos e as dificuldades que muitos professores enfrentam ao ensinar os conteúdos matemáticos. Crenças que eles trazem de sua trajetória de vida escolar, e o desafio de ensinar para seus estudantes aspectos que, "muitas vezes, ainda se encontram em processo de elaboração conceitual em matemática, em decorrência da formação lacunar que 
tiveram nas suas formações iniciais" (NACARATO; MOREIRA, 2019, p. 775), no processo de ensino-aprendizagem desse componente curricular.

\subsection{Crenças e desafios no processo de ensino-aprendizagem da matemática}

De acordo com Vila e Callejo (2006, p. 44), “as crenças são uma forma de conhecimento pessoal e subjetivo, que está mais profunda e fortemente arraigado que uma opinião; constroem-se por meio de experiências, informações, percepções, etc., e delas se desprendem algumas práticas" de ensino em matemática, adquiridas no percurso formativo.

Discutir sobre o percurso formativo de professoras que ensinam matemática nos anos iniciais do ensino fundamental é imprescindível nesta pesquisa, já que são profissionais que atuam nos primeiros anos de escolaridade dos estudantes, formando-os, para dar sequência a seus estudos.

Bruno e Silva (2016) consideram que a formação dos professores começa ainda durante sua vida escolar, como estudantes da educação básica, e deve continuar por toda a carreira docente, ou seja, não se restringe à formação inicial, embora este momento formativo seja tão fundamental quanto os outros. Portanto, entender o seu percurso formativo desde a educação básica se faz necessário para compreendermos as crenças e as práticas docentes.

Para Nacarato, Mengali e Passos (2009, p. 23): "Diferentes autores têm discutido o quanto a professora é influenciada por modelos de docentes com os quais conviveu durante a trajetória estudantil, ou seja, a formação profissional docente inicia-se desde os primeiros anos de escolarização". Essas crenças são historicamente vivenciadas pelos estudantes, futuros professores, e podem levá-los a ter repulsa e até certa "birra" da disciplina Matemática.

Desse modo, as crenças sobre a matemática e o seu ensino na trajetória formativa e profissional, segundo Martins e Curi (2020, p. 7), "são constituídas em um processo pessoal e social, pelas experiências adquiridas em sala de aula como professores, no modo de ensinar, bem como nas relações que estabeleceram com o conteúdo aprendido na época de estudantes da educação básica". Tais percepções podem influenciar sua prática profissional negativamente, levando a modelos de aulas monótonas e mecanizadas, que não contribuem para a aprendizagem dos estudantes.

De acordo com Carneiro e Passos (2014b, p. 1116), “as concepções se formam em um processo simultaneamente individual e social, e, em cada indivíduo, elas se constituem tanto por suas experiências pessoais e por sua história de vida como pela relação que ele estabelece com as outras pessoas". Nesse sentido, nossas experiências com a matemática e as práticas de ensino no percurso formativo e profissional são influenciadas pelos professores que tivemos na trajetória estudantil, na educação básica e superior. 
Ficam evidentes as crenças e as dificuldades que muitos professores carregam ao longo de seu desenvolvimento profissional. Como ensinar uma disciplina que você não conhece? Dessa forma, muitos deles transmitem para seus estudantes a visão equivocada da matemática, e estes, em sua maioria, não entendem a essência da disciplina e experienciam na prática de ensino uma matemática cheia de regras e procedimentos.

Segundo Nacarato, Mengali e Passos (2009, p. 35), “é impossível ensinar aquilo sobre o que não se tem um domínio conceitual". Vimos a matemática, muitas vezes, como uma ciência acabada, que não aceita erros, e a aprendizagem desse componente curricular "[...] para muitos se resume no acúmulo de regras e procedimentos" (D’AMBROSIO, 2005, p. 23). Esta visão pode criar obstáculos para o desempenho docente no processo de ensino-aprendizagem da matemática.

\section{2 "Desempacotando" as práticas de ensino em matemática}

Ball e Bass (2000), citados por D’Ambrosio (2005, p. 21, grifo da autora), apresentam uma metáfora útil para discutir os significados do "desempacotamento" na prática docente, "descrevendo a ação do professor como o ato de 'desempacotar' seu próprio conhecimento formal da matemática para entender as construções dos alunos e, ao mesmo tempo, 'desempacotar' o conhecimento destes para analisá-lo a fundo".

Para que este objetivo de "desempacotar" seja alcançado nas práticas de ensino em matemática, Nacarato, Mengali e Passos (2009) ressaltam a importância, nos cursos de formação de professores, da didática da matemática, que articula os fundamentos teóricos e práticos para orientar as ações pedagógicas no ambiente escolar. Dessa forma, didática e formação dos professores devem ser fatores indissociáveis, para proporcionar o conhecimento matemático acessível às novas gerações. As autoras salientam a importância da didática nos cursos de formação de professores, para produzir reflexos positivos no processo de ensino-aprendizagem da matemática e contribuir para que os professores possam "desempacotar" o seu conhecimento matemático e de seus estudantes.

Como formadores de professores, segundo D’Ambrosio (2005, p. 23), "necessitamos explorar e investigar atividades que levem o futuro professor a se dispor a analisar o trabalho dos alunos e, ao mesmo tempo, estimulá-los a desenvolver seu conhecimento matemático de maneira mais completa e complexa", por meio de vivências de metodologias de ensino-aprendizagem que oportunizem aos estudantes a motivação e o desejo para aprender matemática. Desse modo, "quem ensina aprende ao ensinar e quem aprende ensina ao aprender. Quem ensina, ensina alguma coisa a alguém” (FREIRE, 1996, p. 25).

É importante que os cursos de formação de professores possibilitem aos estudantes-futuros professores compreender os conteúdos matemáticos da matriz curricular da educação básica com que 
irão atuar na docência, pois, se o professor vê a matemática como oponente, é muito provável que vivencie na sua prática pedagógica, mesmo sem intenção, inconscientemente, uma matemática difícil, abstrata e complexa para seus estudantes.

Portanto, “desempacotar" a matemática se faz necessário, primeiramente na formação de professores, para que tenham condições de entender o conhecimento matemático de seus estudantes. "Essa perspectiva sugere que a aprendizagem da matemática não ocorre por repetições e mecanizações, mas se trata de uma prática social que requer envolvimento do aluno em atividades significativas" (NACARATO; MENGALI; PASSOS, 2009, p. 34).

Com efeito, essa prática, que proporciona discussões, questionamentos, reflexões e investigações sobre as diferentes formas para ensinar os conteúdos matemáticos, rompe com modelos tradicionais de ensino da matemática que pouco colaboram com a aprendizagem dos estudantes. Nesse processo, “ensino e aprendizagem dialógicos são importantes para a prática de sala de aula [...]” (ALR $\varnothing ;$ SKOVSMOSE, 2006, p. 142), para “desempacotar” a matemática (D’AMBROSIO, 2005), dar voz aos estudantes e ampliar o repertório de saberes, experiências e aprendizagens dos professores que ensinam matemática.

\section{Narrativas sobre a matemática no percurso formativo de professoras dos anos iniciais}

É igualmente fundamental falar sobre as vivências na graduação, para entender os processos formativos e fazer uma ponderação crítico-reflexiva sobre a formação inicial e continuada. Entendemos que a formação inicial não modifica sozinha o grau de profissionalização dos professores, mas partimos do princípio da importância dessa formação, constituída de etapas para capacitação e emancipação profissional. Gatti (2013, p. 56) ressalta "a importância de formar bem os professores da educação básica, com base em filosofia social da educação, com as perspectivas expostas, de se repensar as estruturas e dinâmicas formativas desses docentes, de se ressituar o papel dos formadores de professores".

Indagada, na entrevista narrativa, sobre a sua formação inicial em matemática e as práticas vivenciadas no curso de Pedagogia, Mel revelou que teve poucas experiências com as práticas de ensino em matemática na graduação:

Eu acredito que, apesar de eu ter estudado em uma faculdade que tentava propiciar pra gente uma experiência bem próxima da realidade, todos eram professores que tinham vivenciado a prática na sala de aula, eram professores, tinham sido professores dos anos iniciais, por muitos anos. $O$ que acontece, mesmo assim, eu acho que a gente teve uma experiência, uma experimentação bem pequena, perto do que a gente poderia ter tido. Eu me lembro da gente participar dos momentos de formação com jogos, bem pouco. Acho que foi bem pouco diante de tantas 
perspectivas que a gente tem de tantas possibilidades. (Professora Mel, entrevista narrativa, out. 2020)

Assim como Mel, a professora Carla destaca que acha pouco intensas as práticas de ensino somente nas disciplinas, não só em matemática, mas em todo o curso de Pedagogia: "Eu acho muito pouco só as disciplinas, na verdade eu acho que o curso de Pedagogia é pouco em quase tudo, a gente aprende mesmo é na prática". Desse modo, é importante que o planejamento das aulas contemple mais a vivência de conhecimentos teóricos e práticos, para que os futuros professores participem do processo de ensino-aprendizagem da matemática e das outras áreas do conhecimento nos ambientes formativos da universidade e da educação básica.

As estudantes-professoras, em sua maioria, relataram as dificuldades enfrentadas ao depararse com a sala de aula e com a experiência de estar à frente de uma turma. A partir desta dificuldade, da insegurança sobre a forma como ensinar e o que ensinar, veio a necessidade de cursar a Especialização, de buscar uma formação continuada que orientasse neste caminho formativo.

Silvia enfatiza em sua narrativa que a graduação contribuiu pouco para atuar em sala: "Tanto que veio a necessidade de fazer uma Especialização, quando eu vi a oportunidade de fazer uma Especialização para o ensino de matemática e ciências, eu me agarrei a ela”. Assim também revela a professora Dandara: “[...] estou fazendo a minha segunda Especialização e aí eu consegui ver mais aspectos práticos que a graduação não deu conta, então, foi até um dos motivos que eu busquei a Especialização no Ensino de Ciências e Matemática nos Anos Iniciais, pela minha dificuldade”.

Segundo Nacarato, Mengali e Passos (2009), a lacuna referente à formação inicial coloca essas professoras diante do desafio de ensinar conteúdos específicos de uma forma diferente daquela com que aprenderam. Para isso, é preciso superar as crenças negativas com a matemática. Entretanto, muitas vezes, não conseguimos romper com elas na graduação e, ao nos depararmos com a sala de aula, damo-nos conta de que a matemática enraizada em nossa formação ainda está fortemente presente, pois, em nossas ações pedagógicas em sala de aula, cobramos de nossos estudantes a matemática decorada mecanicamente. Cometemos, portanto, os mesmos erros de nossos antigos professores, conforme narra a professora Dandara: “[...] porque eu não queria trabalhar multiplicação da forma como eu aprendi, trazer a tabuada e simplesmente decorar, eu queria que as crianças construíssem e aí a cada fato que iríamos aprendendo do dois, do três, eu ia trazendo estratégias novas".

Dandara ressalta a importância da vivência de metodologias inovadoras para fazer a exposição dialogada dos conteúdos matemáticos. "Dessa maneira, sem o conhecimento matemático, o futuro professor pode conhecer algumas metodologias promissoras, mas provavelmente não conseguirá extrair delas bons resultados quando (e se) as utilizar em sala de aula" (NAKAYAMA; SILVA, 
2017, p. 13). Com efeito, na formação inicial e continuada é importante estudar e aprofundar teoricamente e na prática os fundamentos da matemática.

$\mathrm{Na}$ realização da pesquisa, percebemos a ênfase das partícipes nas práticas de ensino em matemática vivenciadas no curso de Especialização. Destacaram nas narrativas que os professoresformadores buscaram partilhar nas aulas diferentes metodologias de ensino-aprendizagem. Nesses momentos formativos, é necessário que a prática seja tomada como ponto de partida, para que seja problematizada e seja objeto de reflexão, conforme salientam Nacarato, Mengali e Passos (2009). Uma das práticas vivenciadas nas aulas desse curso foram os jogos, que marcaram muito a turma, e as estudantes-professoras reportam a importância dessa metodologia em sala de aula.

A disciplina “Tendências no Ensino de Matemática nos Anos Iniciais", estudada no curso de Especialização, no segundo semestre de 2019, com a carga horária de 45 horas, oportunizou que as estudantes-professoras se aprofundassem teoricamente e na prática de jogos e atividades matemáticas vivenciados em salas de aula da educação básica, conforme narram as partícipes da pesquisa.

Ao receberem esta solicitação: "Narre uma experiência de uma das disciplinas cursadas na Especialização em Ensino de Ciências e Matemática nos Anos Iniciais que contribuiu para a sua formação matemática e prática pedagógica", as estudantes-professoras relataram a tábua de Pitágoras, vivenciada em sala de aula.

Durante a Especialização tivemos uma disciplina com a professora Jane e com o professor Reginaldo, então tivemos a professora Jane atuando na disciplina com ele. E ela levou pra gente muitas práticas, muitos exemplos de práticas, vivenciamos, fizemos em sala de aula, e aí quando eu comecei a introduzir multiplicação com meus alunos eu levei pra eles um dos recursos que ela havia apresentado pra gente, que eu conhecia, mas não sabia o nome nem como utilizar, que era a tábua de Pitágoras, e na verdade ela apresentou, a gente teve a oportunidade de fazer algumas atividades com este material lá, na Especialização. (Professora Mel, entrevista narrativa, out. 2020)

Uma das estratégias que eu trouxe foi a tábua de Pitágoras. E eu me lembro que nós construímos assim, eu desenhei ela no quadro e as crianças foram percebendo como funcionava, como já tinham uma noção de multiplicação, foi simples entender. Lembro inclusive de ter fixado lá na sala, e eles falavam que não queriam saber mais de tabuada, porque com um simples quadro (a tábua) eles conseguiriam lembrar com mais facilidade, então isso marcou um pouco. (Professora Dandara, entrevista narrativa, out. 2020)

Nos processos formativos, é importante ter oportunidades como esta e outras que a Especialização nos proporcionou. E Serrazina (2012, p. 267) confirma: “O professor tem de ter oportunidades de viver experiências matemáticas do tipo das que se espera que proporcione aos seus alunos, pois só assim poderá cumprir uma das suas funções como professor de Matemática, a de fazer com que os seus alunos aprendam e apreciem a Matemática”. 
Nas narrativas, as estudantes-professoras descreveram outras atividades desenvolvidas durante o curso, como, por exemplo, o trabalho com a boneca Abayomi, que a professora Jane levou para a turma e instigou várias pesquisas e suposições sobre a verdadeira história de seu surgimento, levando a turma a viajar longe, na época dos navios negreiros. Essa história está retratada no nosso diário de bordo, produzido na disciplina “Tendências no Ensino de Matemática nos Anos Iniciais", com direito à réplica da boneca construída na sala de aula da universidade, que muitas estudantesprofessoras relataram ter levado para sua turma nas escolas em que atuavam.

$\mathrm{Na}$ aula, a boneca foi feita com a finalidade de calcular metros com nossos estudantes. Mas, como a imaginação vai longe, as estudantes-professoras usaram a boneca e sua história em várias atividades, como retratam Silvia e Carla:

Acabei de me lembrar da Abayomi, que fiz com os meninos depois que eu aprendi na pós, não fiz com a conotação de ciências e matemática, mas foi uma coisa que eu vi lá e levei pra sala de aula. (Professora Silvia)

Esta atividade da boneca Abayomi, mas na verdade eu voltei mais pra história, porque lá a Jane fazia mais pra gente calcular metros, lembra? Aí eu utilizei esta história para trabalhar África com eles. (Professora Carla)

Fruto de uma Especialização que mostrou que o currículo não pode e não deve ser engessado, mas deve ser, sim, maleável e investigativo - e trabalhou essa ideia. Segundo Serrazina (2012, p. 272), “para além de conhecer a matemática que ensina, o professor tem de conhecer o currículo a ensinar, não se limitando ao conhecimento do ano/ciclo onde está a trabalhar. Deve possuir uma visão global do currículo a ensinar no ensino fundamental [...]”.

"Desempacotar" a matemática - assim foi com o diário de bordo construído na disciplina “Tendências no Ensino de Matemática nos Anos Iniciais”. Nele colocávamos, em todas as aulas, nossas impressões, ideias de aula, poema, desenho, o que aquela aula havia nos inspirado e remetido.

A disciplina "Leitura e Escrita nas Aulas de Matemática nos Anos Iniciais" nos levou a viajar por dentro da literatura infantil e nos mostrou várias possibilidades de trabalhar com ela nas aulas de matemática. A professora Carla destacou em sua narrativa que esta disciplina marcou bastante seu processo formativo e que ela funciona muito bem na prática: "A disciplina da Cida, que foi o letramento matemático com base nos livros infantis, eu também acho muito importante. É uma coisa que sempre funciona muito bem com as crianças".

A professora Silvia também enfatizou em sua narrativa que a disciplina marcou positivamente seu percurso formativo: “A disciplina da Cida, por causa dos livros de literatura. Foi muito legal o 
jeito como ela trouxe pra gente, as experiências, tudo, a forma como a gente apresentou os livros foi bem legal”.

Já a professora Dandara narrou como foi trabalhar na prática com a literatura infantil, para ensinar matemática para seus estudantes do $3^{\circ}$ ano do ensino fundamental, e como a literatura auxiliou seus estudantes a desconstruir/construir uma nova visão de problemas matemáticos.

A partir da utilização do livro Poemas Problemas que tinha outra forma de fazer problemas que não estavam acostumados. Porque eu peguei crianças do $3 .^{\circ}$ ano, então, de certa forma, não é que elas já vêm formatadas, mas já vêm com uma concepção do que é problema do tipo: João tinha duas balas, ganhou mais três. Com quantas ele ficou? E aí quando eu trouxe, a partir das experiências da Especialização, o livro Poemas Problemas, eles viram outra configuração de problemas. No início teve até uma dificuldade que eles falaram que aquilo estava muito difícil, que aquilo ali não era problema e aí eles até desconstruíram uma visão. Até falei que teria outras formas de fazer problemas, que o problema configurava como isso mesmo, que não era simplesmente manipular os números, tinha um pensar ali. Depois que eles começaram a entrar no livro, eles ficaram instigados, principalmente com as figuras xerocadas, tinha muito envolvimento da turma ali.

As estudantes-professoras também destacaram em suas narrativas as aulas instigantes da disciplina "Educação Matemática: Concepções e Aspectos Filosóficos", estudada no curso de Especialização, no primeiro semestre de 2019, com a carga horária de 45 horas.

Todas as aulas eu achei importantes, principalmente nestes aspectos, mas a da Margareth, a forma como ela fazia, eu não sei se você tinha esta sensação, era como se a gente fosse descobrindo aquele mundo dela, como se a gente fosse o aluno. Então, a Margareth tem uma visão muito legal neste aspecto, muito bacana, ela manda muito bem, e ela é matemática, por ela ter este conhecimento matemático, né? Ela também trabalhou muitos anos com educação básica e isso faz uma diferença danada. (Professora Carla, entrevista narrativa, out. 2020)

Mel relata em sua narrativa as reflexões que a professora dessa disciplina trouxe para suas práticas de ensino: "A disciplina da professora Margareth, ela trazia bastantes reflexões pra nossa prática, pra nossa realidade como professores do ensino de matemática. Foi muito bacana”.

Foram aulas instigantes e marcantes, que nos levaram a refletir e repensar nossas práticas em sala de aula. Nesse contexto, "o conjunto das concepções de um indivíduo forma um sistema que não é estático, imutável, mas dinâmico, podendo sofrer mudanças e reestruturações decorrentes de suas experiências" (CARNEIRO; PASSOS, 2014b, p. 1115).

Essas experiências compartilhávamos uns com os outros - nossos medos, angústias, desafios que enfrentávamos todos os dias na escola básica. Não era simplesmente uma sala de aula, com uma concepção engessada, estudantes sentados um atrás do outro para escutar a professora explicar o conteúdo. Lá era especial, sentávamos em roda, não éramos simplesmente estudantes, éramos mais: 
os professores e colegas. Todos nós virávamos psicólogos, o que nos levava a belas risadas, grupo sem igual. Ao analisar sobre a Especialização, a professora Carla afirma: "Um grupo bacana, os professores muito competentes, achei muito bacana o lado humano nesta Especialização”.

A professora Dandara também aponta sua análise sobre a Especialização e menciona a forma como as conversas entre colegas em sala de aula a ajudaram em sua prática e como aprendemos uns com os outros.

Éramos uma turma muito falante, então, eu aprendi muito com as colegas, não só com os formadores, muito com as colegas, porque tinha um espaço de fala, aí você vai vendo.

- Olha só o fulano! Fez assim, também vou fazer.

Se aprende com a experiência do outro, então, eu acredito que sim, a Especialização atendeu muito as minhas expectativas e me ajudou muito na prática, na desconstrução, na concepção no teórico e no prático.

Segundo Bairral (2005, p. 50), “é possível aos professores aprender quando compartilham seriamente suas experiências profissionais e refletem criticamente sobre elas". Era assim na Especialização: refletíamos criticamente sobre as nossas práticas, sem deixar de lado a nossa sensibilidade como professoras, pois "é fundamental que o professor conheça as definições, mas também tenha a sensibilidade necessária para compreender quando e como pode trabalhar com seus alunos" (SERRAZINA, 2012, p. 269).

$\mathrm{Na}$ análise das narrativas das estudantes-professoras, evidenciamos que o curso de Especialização contribuiu para as práticas de ensino em matemática nos anos iniciais e para a articulação entre teoria e prática. Mas devemos destacar que somos seres inacabados (FREIRE, 1996) e precisamos viver em constante construção. Assim, a continuidade do percurso formativo contribui com nossas práticas, para que possamos vivenciar com os estudantes um ensino de qualidade que propicie um aprendizado significativo com as suas vivências de mundo. Portanto, um ensino que faça sentido para ambos, que consiga ir além dos currículos.

\section{Considerações finais}

De acordo com os resultados da pesquisa com a participação de quatro estudantes-professoras, destacamos que a formação inicial deixou algumas lacunas que nos levaram a cursar a Especialização em Ensino de Ciências e Matemática nos Anos Iniciais, na tentativa de vivenciar uma matemática diferente na prática pedagógica, de deixar para trás as concepções de uma Educação Matemática difícil, monótona. Esse curso foi importante para todas as estudantes-professoras entrevistadas, que demonstraram a importância dele para a sua formação, narraram sobre ela e enfatizaram a satisfação de seus estudantes com as atividades experienciadas em sala de aula. 
A pesquisa aponta a relevância de uma formação continuada consistente para os professores que ensinam matemática, uma vez que há uma relação estreita entre a qualidade do ensino realizado e o tipo de formação que esse professor recebeu ao longo da sua vida acadêmica.

As partícipes da pesquisa revelaram nas narrativas o quanto foi importante, significativo e marcante participar do curso de Especialização. Com efeito, todos os encontros formativos da Especialização propiciaram o compartilhamento de saberes, experiências e aprendizagens da matemática no nosso percurso formativo. Além disso, oportunizaram-nos aprendizagens da docência para vivenciarmos com os estudantes em aulas de matemática.

É perceptível, nas narrativas das participantes da pesquisa, o envolvimento com o processo de ensino-aprendizagem e a participação no curso de Especialização para aprofundamento dos fundamentos teórico-práticos da matemática. Narraram que venceram o cansaço da carga horária semanal de trabalho docente para realizar a pós-graduação no turno noturno com "a alegria necessária ao que-fazer docente" (FREIRE, 1996, p. 161), que propiciou experienciar diferentes práticas de ensino em matemática, que tornaram as aulas mais prazerosas, dinâmicas e participativas.

\section{Referências}

ALRØ, Helle; SKOVSMOSE, Ole. Diálogo e aprendizagem em educação matemática. Tradução de Orlando de Andrade Figueiredo. Belo Horizonte: Autêntica, 2006.

BAIRRAL, Marcelo Almeida. Desenvolvendo-se criticamente em matemática: a formação continuada em ambientes virtualizados. In: FIORENTINI, Dario; NACARATO, Adair Mendes (org.). Cultura, formação e desenvolvimento profissional de professores que ensinam matemática: investigando e teorizando a partir da prática. São Paulo: Musa; Campinas, SP: GEPFPM-PRAPEM-FE/UNICAMP, 2005. p. 49-67.

BOLÍVAR, Antonio; DOMINGO, Jesús; FERNÁNDEZ, Manuel. La investigación biográficonarrativa en educación: enfoque y metodología. Madri: Editorial La Muralla, 2001.

BRUNO, Adriana Rocha; SILVA, Judilma Aline Oliveira. Os processos de docência: transformações enredadas. In: CARNEIRO, Reginaldo Fernando; FLÔR, Cristhiane Carneiro Cunha (org.). Formação de Professores para a educação básica: desafios enfrentados e cenários possíveis. Juiz de Fora: Editora UFJF, 2016. p. 29-54.

CARNEIRO, Reginaldo Fernando; FLÔR, Cristhiane Carneiro Cunha. Apresentação. In: CARNEIRO, Reginaldo Fernando; FLÔR, Cristhiane Carneiro Cunha (org.). Formação de Professores para a educação básica: desafios enfrentados e cenários possíveis. Juiz de Fora: Editora UFJF, 2016. p. 11-26.

CARNEIRO, Reginaldo Fernando; PASSOS, Cármen Lúcia Brancaglion. Apresentação: Matemática nos anos iniciais. Educação \& Realidade, Porto Alegre, v. 39, n. 4, p. 977-984, out./dez. 2014a. ISSN 2175-6236. DOI 10.1590/S2175-62362014000400002. Disponível em: https://www.scielo.br/pdf/edreal/v39n4/02.pdf. Acesso em: 17 jul. 2020. 
CARNEIRO, Reginaldo Fernando; PASSOS, Cármen Lúcia Brancaglion. Concepções de matemática de alunas-professoras dos anos iniciais. Educação \& Realidade, Porto Alegre, v. 39, n. 4, p. 1113-1133, out./dez. 2014b. ISSN 2175-6236. DOI 10.1590/S2175-62362014000400009. Disponível em: https://www.scielo.br/pdf/edreal/v39n4/09.pdf. Acesso em: 17 jul. 2020.

CLANDININ, D. Jean; CONNELLY, F. Michael. Pesquisa narrativa: experiência e história na pesquisa qualitativa. Tradução do Grupo de Pesquisa Narrativa e Educação de Professores (GPNEP) ILEEL/UFU. 2. ed. rev. Uberlândia: EDUFU, 2015.

COSTA, Jaqueline de Morais; PINHEIRO, Nilcéia Aparecida Maciel; COSTA, Ercules. A formação para matemática do professor de anos iniciais. Ciência \& Educaçãa, Bauru, v. 22, n. 2, p. 505-522, 2016. ISSN 1980-850X. DOI 10.1590/1516-731320160020014. Disponível em: https://www.scielo.br/pdf/ciedu/v22n2/1516-7313-ciedu-22-02-0505.pdf. Acesso em: 15 jul. 2020.

D’AMBROSIO, Beatriz Silva. Conteúdo e metodologia na formação de professores. In: FIORENTINI, Dario; NACARATO, Adair Mendes (org.). Cultura, formação e desenvolvimento profissional de professores que ensinam matemática: investigando e teorizando a partir da prática. São Paulo: Musa; Campinas, SP: GEPFPM-PRAPEM-FE/UNICAMP, 2005. p. 20-32.

FIORENTINI, Dario; LORENZATO, Sergio. Investigação em educação matemática: percursos teóricos e metodológicos. Campinas, SP: Autores Associados, 2012.

FREIRE, Paulo. Pedagogia da autonomia: saberes necessários à prática educativa. 18. ed. São Paulo: Paz e Terra, 1996.

GATTI, Bernardete Angelina. Educação, escola e formação de professores: políticas e impasses. Educar em Revista, Curitiba, n. 50, p. 51-67, out./dez. 2013. ISSN 1984-0411. Disponível em: https://www.scielo.br/pdf/er/n50/n50a05.pdf. Acesso em: 25 set. 2020.

MARTINS, Priscila Bernardo; CURI, Edda. As concepções, crenças e mitos evidenciados por um grupo de professores do ciclo interdisciplinar da rede municipal da cidade de São Paulo. Revista Internacional de Pesquisa em Didática das Ciências e Matemática, Itapetininga, v. 1, e020011, p. 1-24, 2020. ISSN 2675-4258. Disponível em:

https://periodicoscientificos.itp.ifsp.edu.br/index.php/revin/article/view/109. Acesso em: 25 set. 2020.

NACARATO, Adair Mendes; MENGALI, Brenda Leme da Silva; PASSOS, Cármen Lúcia Brancaglion. A matemática nos anos iniciais do ensino fundamental: tecendo fios do ensinar e do aprender. Belo Horizonte: Autêntica, 2009.

NACARATO, Adair Mendes; MOREIRA, Kátia Gabriela. A colaboração entre professoras como prática de formação para ensinar matemática nos anos iniciais. Revista de Educação Pública, Cuiabá, v. 28, n. 69, p. 767-791, set./dez. 2019. ISSN 2238-2097. DOI 10.29286/rep.v28i69.7012. Disponível em:

https://periodicoscientificos.ufmt.br/ojs/index.php/educacaopublica/article/view/7012. Acesso em: 25 set. 2020.

NAKAYAMA, Bárbara Cristina Moreira Sicardi; SILVA, Jaqueline Ferreira da. Formação matemática do professor polivalente: um estudo metanalítico. Revista de Estudos Aplicados em Educação (REAe), São Paulo, v. 2, n. 3, p. 3-16, jan./jun. 2017. DOI 10.13037/rea-e.vol2n3.4458. 
Disponível em: https://seer.uscs.edu.br/index.php/revista_estudos_aplicados/article/view/4458. Acesso em: 25 set. 2020.

SERRAZINA, Maria de Lurdes Marquês. Conhecimento matemático para ensinar: papel da planificação e da reflexão da formação de professores. Revista Eletrônica de Educação, São Carlos, SP, v. 6, n. 1, p. 266-283, maio 2012. ISSN 1982-7199. DOI 10.14244/19827199. Disponível em: http://www.reveduc.ufscar.br/index.php/reveduc/article/view/355/162. Acesso em: 14 out. 2020.

SOUZA, Elizeu Clementino de; CRUZ, Núbia da Silva. Pesquisa (auto)biográfica: sentidos e implicações para o campo educacional. In: AMADO, João; CRUSOÉ, Nilma Margarida de Castro (org.). Referenciais teóricos e metodológicos de investigação em educação e ciências sociais. Vitória da Conquista: Edições UESB, 2017. p. 167-194.

VIEIRA JUNIOR, Wagner Alvarenga; OLIVEIRA, Sandra Alves de. A formação matemática no percurso formativo do pedagogo: contribuições e limitações. In: ENCONTRO DE PRÁTICAS EM CIÊNCIAS E MATEMÁTICA NOS ANOS INICIAIS, 4., 2019, Juiz de Fora. Anais [...]. Juiz de Fora: UFJF, 2019. p. 22-30.

VIEIRA JUNIOR, Wagner Alvarenga; OLIVEIRA, Sandra Alves de. Narrativas da formação e da atuação do pedagogo no processo de ensino e aprendizagem da matemática nos anos iniciais do ensino fundamental. Revista Paranaense de Educação Matemática, Campo Mourão, PR, v. 9, n. 19, p. 704-730, jul./out. 2020. ISSN 2238-5800. DOI 10.33871/22385800.2020.9.19.704-730.

Disponível em: http://rpem.unespar.edu.br/index.php/rpem/article/viewArticle/2420. Acesso em: 11 nov. 2020.

VILA, Antoni; CALLEJO, María Luz. Matemática para aprender a pensar: o papel das crenças na resolução de problemas. Porto Alegre: Artmed, 2006. 